\title{
Growth hormone improves body composition, fasting blood glucose, glucose tolerance and liver triacylglycerol in a mouse model of diet-induced obesity and type 2 diabetes
}

\author{
E. O. List • A. J. Palmer • D. E. Berryman • B. Bower • \\ B. Kelder • J. J. Kopchick
}

Received: 2 February 2009 /Accepted: 5 May 2009/Published online: 26 May 2009

(C) Springer-Verlag 2009

\begin{abstract}
Aims/hypothesis Growth hormone has been used experimentally in two studies to treat individuals with type 2 diabetes, with both reporting beneficial effects on glucose metabolism. However, concerns over potential diabetogenic actions of growth hormone complicate its anticipated use to treat type 2 diabetes. Thus, an animal model of type 2 diabetes could help evaluate the effects of growth hormone for treating this condition.

Methods Male C57BL/6J mice were placed on a high-fat diet to induce obesity and type 2 diabetes. Starting at 16 weeks of age, mice were treated once daily for 6 weeks with one of four different doses of growth hormone. Body weight, body composition, fasting blood glucose, insulin, glucose tolerance, liver triacylglycerol, tissue weights and blood chemistries were determined.

Results Body composition measurements revealed a dosedependent decrease in fat and an increase in lean mass. Analysis of fat loss by depot revealed that subcutaneous and mesenteric fat was the most sensitive to growth hormone treatment. In addition, growth hormone treatment

E. O. List • D. E. Berryman • B. Bower · B. Kelder •

J. J. Kopchick $(\triangle)$

Edison Biotechnology Institute, Ohio University,

101 Konneker Research Laboratories, 1 Water Tower Drive,

The Ridges, Athens, OH 45701, USA

e-mail: kopchick@ohio.edu

\section{A. J. Palmer $\cdot$ D. E. Berryman}

School of Human and Consumer Sciences, College of Health and Human Services, Ohio University,

Athens, OH, USA

\section{J. J. Kopchick}

Department of Biomedical Sciences, College of Osteopathic

Medicine, Ohio University,

Athens, OH, USA
\end{abstract}

resulted in improvement in glucose metabolism, with the highest dose normalising glucose, glucose tolerance and liver triacylglycerol. In contrast, insulin levels were not altered by the treatment, nor did organ weights change. However, fasting plasma leptin and resistin were significantly decreased after growth hormone treatment.

Conclusions/interpretation Growth hormone therapy improves glucose metabolism in this mouse model of obesity and type 2 diabetes, providing a means to explore the molecular mechanism(s) of this treatment.

Keywords Body composition - Glucose tolerance · Growth hormone $\cdot$ Hyperglycaemia $\cdot$ Hyperinsulinaemia . Obesity · Triacylglycerol - Type 2 diabetes

\section{Abbreviation \\ tPAI-1 Tissue plasminogen activator inhibitor-1}

\section{Introduction}

Recombinant human growth hormone is a drug approved for a variety of clinical conditions. It has positive effects on body composition [1]. Increased protein accretion in muscle and lipolysis in adipose tissue are biological consequences of growth hormone action and together promote a lean phenotype, as reviewed [2]. Despite its ability to improve body composition, growth hormone has also been described as a diabetogenic agent with the ability to inhibit the action of insulin [1, 3, 4]. Thus, one concern about use of growth hormone for treating type 2 diabetes is the possibility of developing or worsening existing insulin resistance.

Nevertheless, two human studies using growth hormone therapy to treat type 2 diabetes have both, surprisingly, reported improvements in glucose and insulin levels, and 
insulin sensitivity $[5,6]$. While growth hormone has been studied frequently as treatment for non-diabetic, obese individuals, with mixed results [5-12], research on its use for treating human type 2 diabetes is limited to the two studies mentioned above. Furthermore, there are no studies using growth hormone in animal models of type 2 diabetes, so additional insight is lacking. Thus, the question of whether growth hormone can be safely used to treat type 2 diabetes remains unresolved, therefore an animal model that can more fully evaluate the impact of growth hormone treatment on physiology and organ function would be useful.

Development of an animal model would be useful for other reasons. Studies using humans can be difficult to interpret, due to heterogeneous genotypes, as well as difficulty in controlling patient activities like diet, exercise and medication $[6,11,13]$. Mouse models, in contrast, are often used to supplement knowledge of human diseases and offer other advantages. For example, mice have relatively similar physiologies to humans, while pure bred stains are genetically more uniform than humans and exogenous factors, which are hard to control in humans, can be easily controlled in a laboratory setting. Therefore, it is imperative to develop a mouse model to evaluate the safety and effectiveness of growth hormone therapy in the treatment of type 2 diabetes.

In the current study, an established mouse model of dietinduced obesity and type 2 diabetes [14-18] was used to evaluate the impact of growth hormone treatment on type 2 diabetes. Type 2 diabetic mice (defined here as mice with significantly elevated blood glucose and insulin compared with control mice) were treated with a wide range of growth hormone doses for 6 weeks while maintained on a high-fat diet. Metabolic variables relevant to obesity (body weight, body composition, adipokine levels, organ weights and liver triacylglycerol), diabetes (glucose, glucose tolerance, insulin levels) and growth hormone status (IGF-1 levels, organ weights) were monitored.

\section{Methods}

Generation of a mouse model of diet-induced obesity and type 2 diabetes Induction of a mouse model of obesity and type 2 diabetes using a high-fat diet has been reported previously [14-18]. We purchased 49 male C57Bl/6 J mice (Jackson Laboratories, Bar Harbor, ME, USA) at 21 days of age and divided them into two experimental groups. The first group $(n=42)$ was placed on a high-fat diet (D12492; Research Diets, New Brunswick, NJ, USA), while the second group $(n=7)$ was placed on standard laboratory rodent chow (ProLab RMH 3000; LabDiet, Richmond, VA, USA). In the high-fat diet, $20 \%$ of energy was from carbohydrates, $20 \%$ from protein and $60 \%$ from fat. The standard low-fat diet supplied $60 \%$ of energy from carbohydrates, $26 \%$ from protein and $14 \%$ from fat. Mice were maintained on the respective diets throughout the study, including during the growth hormone treatment phase. Mice were housed two to three per cage, with free access to food and water. The cages were kept in a temperature- and humidity-controlled room and exposed to a $14 \mathrm{~h} \mathrm{light} / 10 \mathrm{~h}$ dark cycle. All procedures were approved by the Ohio University Institutional Animal Care and Use Committee and fully complied with all federal, state and local policies.

Growth hormone treatment Purified recombinant bovine growth hormone was a gift from Monsanto (St Louis, MO, USA). Purified growth hormone powder was suspended in PBS. All four doses were prepared on the same day prior to the study and stored as daily aliquots frozen at $-80^{\circ} \mathrm{C}$. Individual aliquots were thawed just prior to use. The 6week phase of daily subcutaneous growth hormone injections (referred to as growth hormone treatment phase) started after 16 weeks on the high-fat diet and continued to week 22 . For mice on the high-fat diet, growth hormone was administered at four different doses: 0.005, 0.05, 0.5 and $5 \mu \mathrm{g}$ growth hormone $\mathrm{g}^{-1}$ day $^{-1}$ (referred to as HF-0.005, HF- 0.05 , HF- 0.5 and HF-5 in the text). In addition, a low-fat diet group and a high-fat diet group of mice were injected with an equal volume of PBS and served as controls (referred to as LF-PBS and HF-PBS, respectively). Seven to nine mice were used per group. Injection sites were rotated weekly between the neck and the lower back to minimise skin irritations. The injections occurred at 15.00 hours $\pm 2 \mathrm{~h}$ daily.

Weight and body composition measurements Total body weight was assessed weekly throughout the study. Body composition was measured weekly using a Bruker Minispec (The Woodlands, TX, USA) during the 6 week growth hormone treatment phase.

Blood glucose measurements and collection of plasma During the growth hormone treatment phase, fasting blood glucose was determined and fasting plasma samples were collected every 2 weeks. Blood collection was performed by cutting $\sim 1 \mathrm{~mm}$ off the tip of the tail and collecting $200 \mu \mathrm{l}$ of blood into heparinised capillary tubes. Blood collection occurred between 09.00 and 11.00 hours following a $12 \mathrm{~h}$ fast. Plasma was obtained by centrifugation at $4^{\circ} \mathrm{C}$ for $10 \mathrm{~min}$ at $7,000 \mathrm{~g}$ and was stored at $-80^{\circ} \mathrm{C}$ until further analysis.

Plasma measurements IGF-1 concentrations were determined using a mouse IGF-1 ELISA kit (DSL-10-29200; Diagnostic Systems Laboratories, Webster, TX, USA) following the manufacturer's instructions. The sensitivity 
of the IGF-1 assay was $1.3 \mathrm{ng} / \mathrm{ml}$. Plasma adipokines and cytokines were measured using Mouse Adipokine Lincoplex and Mouse Cytokine Lincoplex panels (Linco Diagnostic Services, St Charles, MO, USA). Insulin concentrations were determined using an ultra-sensitive mouse insulin ELISA kit (ALPCO Diagnostics, Windham, $\mathrm{NH}, \mathrm{USA}$ ) as per the manufacturer's instructions.

Glucose tolerance test Glucose tolerance tests were performed during the final week of injections. Mice were fasted for $12 \mathrm{~h}$ prior to the measurements. Each mouse received an intraperitoneal injection of a $10 \%$ glucose solution at $0.01 \mathrm{ml} / \mathrm{g}$ body weight. Blood glucose measurements were performed in duplicate using a glucometer (OneTouch LifeScan, Milpitas, CA, USA) before the injection and at 60, 120 and $180 \mathrm{~min}$ after the injection. The fasting blood glucose and glucose tolerance tests were timed to be assessed in the mornings and $\sim 18 \mathrm{~h}$ after the last daily growth hormone injection.

Tissue collection Animals were killed by cervical dislocation after 22 weeks of diet treatment and 6 weeks of daily growth hormone injections. Liver, kidney, heart, muscle and adipose tissue (inguinal subcutaneous, epididymal, retroperitoneal, mesenteric fat pads) were collected, weighed, flash-frozen in liquid nitrogen and stored at $-80^{\circ} \mathrm{C}$ until further analysis.

Liver triacylglycerol content Liver tissue was used for extraction and measurement of triacylglycerol levels as described previously [19]. Briefly, samples were digested in a $3 \mathrm{~mol} / 1 \mathrm{KOH}$ in $65 \%$ (vol./vol.) ethanol solution overnight. A triacylglycerol GPO kit (Pointe Scientific, Canton, MI, USA) was used to measure glycerol content of the samples. Calculations were performed to estimate triacylglycerol levels, assuming the average molecular mass of triacylglycerol is $0.885 \mathrm{kDa}(885 \mathrm{~g} / \mathrm{mol})$.

Statistical analysis Data are presented as mean \pm SEM. Statistics were performed on weights, body composition measurements, plasma measurements and organ weights using SPSS version 14.0 (Chicago, IL, USA). Comparisons were made using a univariate ANOVA with Tukey's honestly significant difference post hoc test. For withinand between-group comparison of longitudinal data, repeated-measures ANOVA was used. Differences were considered significant at $p<0.05$.

\section{Results}

Generation of mouse model of obesity and type 2 diabetes mice After 16 weeks, the high-fat group of mice weighed significantly $(42.6 \pm 0.7 \mathrm{~g})$ more than those fed the low-fat diet $(28.7 \pm 1.0 \mathrm{~g})$. This increase in weight was due, in part, to fat mass accumulation $(14.4 \pm 1.5 \mathrm{~g}$ on high-fat diet vs $0.99 \pm 0.2 \mathrm{~g}$ on low-fat diet). Insulin $(483 \pm 33 \mathrm{pmol} / \mathrm{l})$ and glucose $(12.7 \pm .043 \mathrm{mmol} / \mathrm{l})$ levels were also significantly elevated in the high-fat fed compared with low-fat fed control animals $(63.9 \pm 12 \mathrm{pmol} / \mathrm{l}$ and $7.88 \pm 0.63 \mathrm{mmol} / \mathrm{l}$, respectively). These results were similar to those reported previously [14, 16-18] and show that the high-fat fed mice used in the growth hormone treatment phase were obese and diabetic before treatment began.

Growth hormone stimulated IGF-I production Plasma IGF1 levels were monitored to evaluate the potency of the bovine growth hormone treatment regime. Plasma IGF-1 levels of the LF-PBS injected group were significantly lower than all high-fat fed groups $(F[5,43]=27.373$, $p<0.05$ ) where 5 represents the degrees of freedom between groups and 43 represents the degrees of freedom within groups (Fig. 1). Of the high-fat fed mice, only the highest dose of growth hormone was able to significantly elevate plasma IGF-1 levels above those of the control group.

Body weight and composition changes with growth hormone treatment No significant difference in body weight was observed between or among the groups fed the high-fat diet even with the various growth hormone treatments $(F$ $[5,45]=0.502, p=0.78$ ) (Table 1). However, there were dramatic alterations in body composition between the highfat fed groups following growth hormone treatment (Figs 2 and 3). Specifically, the highest two doses of growth hormone resulted in a dose-dependent decrease in fat mass in high-fat fed mice $(F[5,43]=41.1, p<0.001)$ (Fig. 2). The decrease in adiposity was statistically significant by the end of the first week of growth hormone treatment. Interestingly, the peak loss in fat mass occurred after only 2 weeks, even though the control mice and those treated

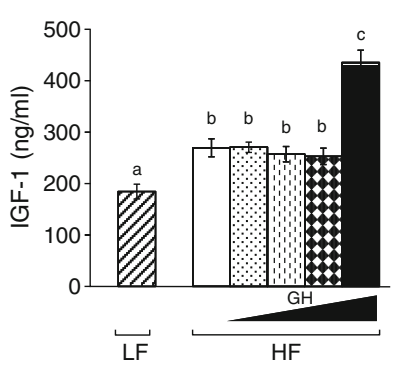

Fig. 1 Plasma IGF-1 measurements $(\mathrm{ng} / \mathrm{ml})$ at week6 in mice on the low-fat (LF) diet injected with PBS (hatched bars), high-fat (HF) diet injected with PBS (white bars), or in mice on the high-fat diet injected with increasing doses of growth hormone $(\mathrm{GH})$ as follows: $0.005 \mu \mathrm{g} / \mathrm{g}$ (spotted bars), $0.05 \mu \mathrm{g} / \mathrm{g}$ (vertical dashed bars), $0.5 \mu \mathrm{g} / \mathrm{g}$ (chequered bars) or $5 \mu \mathrm{g} / \mathrm{g}$ (black bars). Data are expressed as mean \pm SEM. Means shown with a common superscript letter are not significantly different, $p>0.05$ 
Table 1 Whole body weight, organ weight and the weights of four adipose tissue depots following 6 weeks of growth hormone treatment

\begin{tabular}{|c|c|c|c|c|c|c|}
\hline \multirow[t]{2}{*}{ Variables } & \multicolumn{6}{|l|}{ Study groups } \\
\hline & LF-PBS & HF-PBS & HF-0.005 & HF-0.05 & HF-0.5 & $\mathrm{HF}-5$ \\
\hline$n$ & 7 & 8 & 8 & 8 & 8 & 9 \\
\hline \multicolumn{7}{|l|}{ Body weight (g) } \\
\hline Pre-treatment & $28.7 \pm 1.04^{\mathrm{a}}$ & $42.8 \pm 1.50^{b}$ & $43.0 \pm 1.52^{b}$ & $42.6 \pm 1.79^{b}$ & $42.2 \pm 1.50^{\mathrm{b}}$ & $42.6 \pm 1.83^{b}$ \\
\hline End of treatment & $28.8 \pm 1.05^{\mathrm{a}}$ & $47.5 \pm 1.31^{\mathrm{b}}$ & $46.7 \pm 1.70^{\mathrm{b}}$ & $46.7 \pm 2.14^{b}$ & $43.7 \pm 1.52^{b}$ & $43.0 \pm 1.42^{b}$ \\
\hline \multicolumn{7}{|l|}{ Organ weight (g) } \\
\hline Liver & $1.49 \pm 0.12^{\mathrm{a}}$ & $1.64 \pm 0.10^{\mathrm{a}}$ & $1.55 \pm 0.14^{\mathrm{a}}$ & $1.53 \pm 0.12^{\mathrm{a}}$ & $1.24 \pm 0.11^{\mathrm{a}}$ & $1.44 \pm 0.08^{\mathrm{a}}$ \\
\hline Heart & $0.14 \pm 0.12^{\mathrm{a}}$ & $0.15 \pm 0.01^{\mathrm{a}}$ & $0.17 \pm 0.13^{\mathrm{a}}$ & $0.14 \pm 0.005^{\mathrm{a}}$ & $0.15 \pm 0.01^{\mathrm{a}}$ & $0.18 \pm 0.01^{\mathrm{a}}$ \\
\hline Kidney & $0.34 \pm 0.02^{\mathrm{a}, \mathrm{b}}$ & $0.36 \pm 0.01^{\mathrm{a}, \mathrm{b}}$ & $0.31 \pm 0.03^{\mathrm{a}}$ & $0.33 \pm 0.01^{\mathrm{a}, \mathrm{b}}$ & $0.33 \pm 0.02^{\mathrm{a}, \mathrm{b}}$ & $0.38 \pm 0.01^{\mathrm{b}}$ \\
\hline Spleen & $0.19 \pm 0.02^{\mathrm{a}}$ & $0.19 \pm 0.02^{\mathrm{a}}$ & $0.19 \pm 0.03^{\mathrm{a}}$ & $0.19 \pm 0.03^{\mathrm{a}}$ & $0.24 \pm 0.03^{\mathrm{a}}$ & $0.26 \pm 0.02^{\mathrm{a}}$ \\
\hline \multicolumn{7}{|l|}{ Adipose depot (g) } \\
\hline Subcutaneous & $0.18 \pm 0.01^{\mathrm{a}}$ & $2.61 \pm 0.27^{\mathrm{b}}$ & $2.77 \pm 0.26^{b}$ & $2.80 \pm 0.36^{b}$ & $2.24 \pm 0.35^{b}$ & $1.06 \pm 0.13^{\mathrm{a}}$ \\
\hline Epididymal & $0.41 \pm 0.03^{\mathrm{a}}$ & $2.27 \pm 0.18^{b}$ & $2.06 \pm 0.15^{b}$ & $2.10 \pm 0.14^{b}$ & $1.99 \pm 0.15^{b}$ & $1.45 \pm 0.10^{\mathrm{c}}$ \\
\hline Retroperitoneal & $0.20 \pm 0.12^{\mathrm{a}}$ & $0.82 \pm 0.06^{b}$ & $0.69 \pm 0.05^{b}$ & $0.75 \pm 0.03^{b}$ & $0.62 \pm 0.05^{\mathrm{b}, \mathrm{c}}$ & $0.43 \pm 0.02^{\mathrm{a}, \mathrm{c}}$ \\
\hline Mesenteric & $0.12 \pm 0.02^{\mathrm{a}}$ & $1.22 \pm 0.13^{\mathrm{b}}$ & $1.12 \pm 0.13^{b}$ & $1.21 \pm 0.18^{\mathrm{b}}$ & $0.87 \pm 0.13^{\mathrm{b}, \mathrm{c}}$ & $0.60 \pm 0.06^{\mathrm{a}, \mathrm{c}}$ \\
\hline
\end{tabular}

Data are means \pm SEM

Means in the same row without a common superscript letter are significantly different $(p<0.05)$

HF, high-fat diet; LF, low-fat diet

with lower dose growth hormone continued to gain fat mass during the 6 weeks of growth hormone treatment. Thus the total fat mass change after 6 weeks of injections was a net gain of $3.7 \pm 0.4 \mathrm{~g}(12.5 \%)$ in the HF-PBS group, while the HF-5 group had a net loss of $4.1 \pm 0.8 \mathrm{~g}(-11.2 \%)$ over the same period; this represents a difference of $8 \mathrm{~g}$ between untreated high-fat fed mice and those mice treated with the

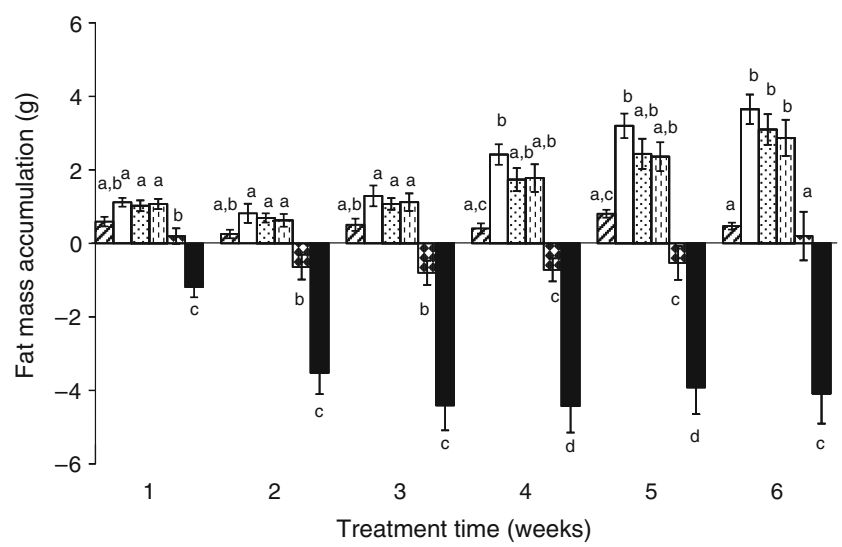

Fig. 2 Fat mass accumulation by week compared with fat mass determined immediately prior to treatment of mice on the low-fat (LF) diet injected with PBS (hatched bars), high-fat (HF) diet injected with PBS (white bars), or in mice on the high-fat diet injected with increasing doses of growth hormone $(\mathrm{GH})$ as follows: $0.005 \mu \mathrm{g} / \mathrm{g}$ (spotted bars), $0.05 \mu \mathrm{g} / \mathrm{g}$ (vertical dashed bars), $0.5 \mu \mathrm{g} / \mathrm{g}$ (chequered bars) or $5 \mu \mathrm{g} / \mathrm{g}$ (black bars). Data are expressed as mean \pm SEM. Means within each week with a common superscript letter are not significantly different $(p>0.05)$ highest level of growth hormone. In terms of per cent body fat, the high-dose growth hormone treatment accounted for a large reduction when compared with high-fat fed control mice, with the latter having $37.4 \%$ mean body fat, while mice receiving high-dose growth hormone $\left(5 \mu \mathrm{g} \mathrm{g}^{-1}\right.$ day $\left.^{-1}\right)$ had $21.4 \%$ mean body fat.

Lean mass differences were also seen. With the highest dose of growth hormone, significant increases in lean mass were observed $(F=[5,43]=66.1, p<0.001)$ (Fig. 3). Unlike

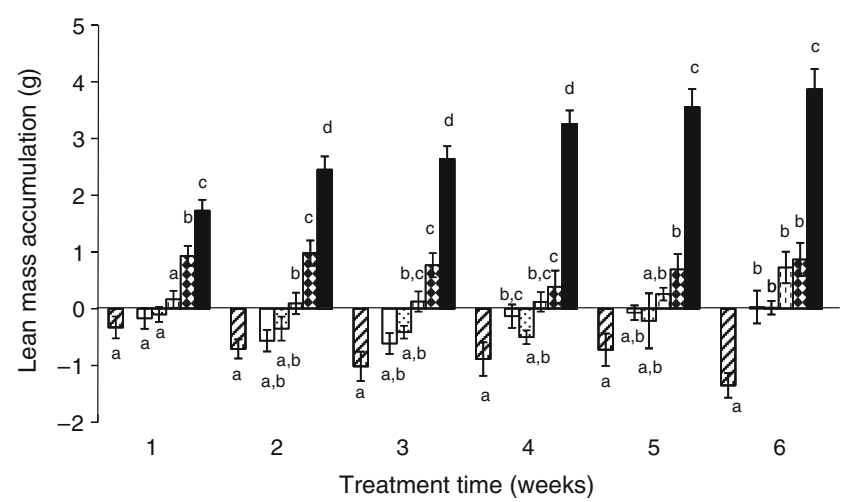

Fig. 3 Lean mass accumulation by week compared with lean mass determined immediately prior to treatment of mice on the low-fat (LF) diet injected with PBS (hatched bars), high-fat (HF) diet injected with PBS (white bars), or in mice on the high-fat diet injected with increasing doses of growth hormone $(\mathrm{GH})$ as follows: $0.005 \mu \mathrm{g} / \mathrm{g}$ (spotted bars), $0.05 \mu \mathrm{g} / \mathrm{g}$ (vertical dashed bars), $0.5 \mu \mathrm{g} / \mathrm{g}$ (chequered bars) or $5 \mu \mathrm{g} / \mathrm{g}$ (black bars). Data are expressed as mean \pm SEM. Means within each week with a common superscript letter are not significantly $(p>0.05)$ 
fat mass reduction, which peaked after 2 weeks of treatment, lean mass continued to increase over the entire 6 weeks of high-dose growth hormone treatment. At the end of the 6 weeks, the mice in the high-dose growth hormone treatment group had gained a mean of $3.9 \mathrm{~g}$ of lean mass. The amounts of lean mass in the HF-PBS, HF0.005 , HF-0.05 and HF-0.5 groups did not differ significantly $(F[5,43]=46.620, p>0.05)$ at the end of the 6 week treatment phase. Fluid as determined by nuclear magnetic resonance was measured, but did not change significantly with growth hormone treatment regardless of dose (data not shown).

Glucose, insulin and glucose tolerance After 6 weeks of growth hormone injections, blood glucose levels were altered significantly among groups (Fig. 4a). The mice with the two highest doses of growth hormone had significantly reduced blood glucose levels compared with PBS-treated mice on the high-fat diet. Surprisingly, the highest dosage of growth hormone decreased fasting blood glucose to a level similar to those of non-diabetic mice fed the low-fat diet (Fig. 4b). Glucose tolerance tests revealed a similar pattern, with improvements in glucose metabolism in mice on higher doses of growth hormone (Fig. 4c). However, plasma insulin levels showed a different trend (Fig. 4b). After 6 weeks of injections, all high-fat fed groups had significantly elevated plasma insulin levels compared with low-fat-fed control mice. Growth hormone treatment, regardless of dosage, had no effect on plasma insulin levels.

Adipokine and cytokine levels Plasma samples from the LFPBS, HF-PBS and the HF-5 growth hormone treatment groups were evaluated for cytokine and adipokine levels
(Table 2). Compared with LF-PBS mice, high-fat feeding resulted in a significant elevation in insulin, leptin, resistin, tissue plasminogen activator inhibitor-1 (tPAI-1) and granulocyte-macrophage colony-stimulating factor. In high-fat fed mice treated with growth hormone, a significant reduction in plasma levels of leptin and tPAI-1 was achieved. In the HF-5 group, only tPAI-1 was reduced with growth hormone treatment to levels similar to those in LFPBS mice.

Organ weights Mean organ weights are shown in Table 1. The weights of heart $(F[5,43]=1.644, p>0.05)$, liver $(F[5$, $43]=1.560, p>0.05)$ and spleen $(F[5,43]=1.721, p>0.05)$ were not altered among any of the treatment groups. Kidney weight in the HF-0.005 group was significantly less than in the HF-5 group; however, these groups were not significantly different from the remaining treatment groups $(F[5,43]=2.914, p>0.05)$. Compared with the HFPBS group, the weight of the four adipose depots was significantly decreased upon treatment with the highest dose of growth hormone. The subcutaneous and mesenteric fat pads showed the greatest per cent decrease $(-59 \%$ and $-51 \%$ respectively) with growth hormone treatment, while the epididymal fat showed the smallest per cent decrease $(-36 \%)$.

Liver triacylglycerol Liver triacylglycerol levels were significantly elevated with high-fat feeding (HF-PBS) compared with LF-PBS controls (Fig. 5). Although no effect was seen with the low growth hormone doses, triacylglycerol levels in the livers of HF-0.5 and HF-5 mice were significantly lower than those in HF-PBS controls and, in fact, were statistically similar to those in LF-PBS controls, suggesting a complete reversal of fatty livers.
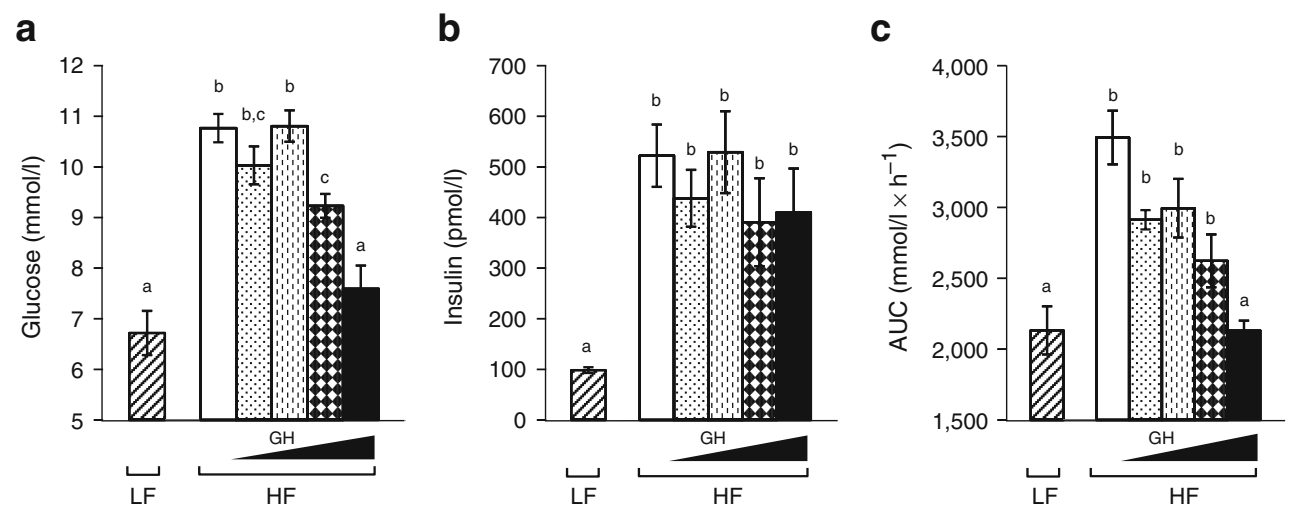

Fig. 4 Glucose metabolism variables following 6 weeks of growth hormone $(\mathrm{GH})$ treatment. a Fasting blood glucose, b fasting plasma insulin and $\mathbf{c}$ intraperitoneal glucose tolerance test in mice on the lowfat (LF) diet injected with PBS (hatched bars), high-fat (HF) diet injected with PBS (white bars), or in mice on the high-fat diet injected with increasing doses of GH as follows: $0.005 \mu \mathrm{g} / \mathrm{g}$ (spotted bars), $0.05 \mu \mathrm{g} / \mathrm{g}$ (vertical dashed bars), $0.5 \mu \mathrm{g} / \mathrm{g}$ (chequered bars) or $5 \mu \mathrm{g} / \mathrm{g}$ (black bars). Data are expressed as mean \pm SEM. Means shown with a common superscript letter are not significantly different, $p>0.05$ 
Table 2 Fasting plasma measurements of low-fat diet-fed mice injected with PBS (LF-PBS), high-fat diet-fed mice injected with PBS (HF-PBS) and high-fat diet-mice treated with $5 \mu \mathrm{g}$ growth hormone $\mathrm{g}^{-1}$ day ${ }^{-1}$ (HF-5)

\begin{tabular}{|c|c|c|c|c|c|c|}
\hline Variables & LF-PBS & HF-PBS & HF-5 & $p$ value $^{\mathrm{a}}$ & $p$ value $^{\mathrm{b}}$ & $p$ value $^{\mathrm{c}}$ \\
\hline$n$ & 7 & 8 & 9 & - & - & - \\
\hline \multicolumn{7}{|l|}{ Adipokine panel } \\
\hline Leptin (pg/ml) & $637 \pm 146$ & $16,839 \pm 2,213$ & $10,189 \pm 1,804$ & $6.2 \times 10^{-6}$ & 0.024 & 0.0002 \\
\hline Resistin (pg/ml) & $353 \pm 26.2$ & $1,275 \pm 92.4$ & $1,099 \pm 176$ & $2.7 \times 10^{-7}$ & 0.38 & 0.0015 \\
\hline tPAI-1 (pg/ml) & $803 \pm 265$ & $1,708 \pm 341$ & $955 \pm 157$ & 0.047 & 0.042 & 0.59 \\
\hline \multicolumn{7}{|l|}{ Cytokine panel } \\
\hline GM-CSF (pg/ml) & $89.3 \pm 9.86$ & $138 \pm 17.3$ & $157 \pm 11.9$ & 0.026 & 0.33 & 0.0005 \\
\hline MCP-1 (pg/ml) & $75.0 \pm 9.54$ & $129 \pm 33.1$ & $144 \pm 30.5$ & 0.14 & 0.72 & 0.061 \\
\hline $\mathrm{TNF}-\alpha(\mathrm{pg} / \mathrm{ml})$ & $8.75 \pm 1.64$ & $12.2 \pm 2.15$ & $10.5 \pm 1.12$ & 0.20 & 0.44 & 0.34 \\
\hline
\end{tabular}

Data are means \pm SEM

${ }^{\mathrm{a}}$ For LF-PBS vs HF-PBS; ${ }^{\mathrm{b}}$ for HF-PBS vs HF-5; ${ }^{\mathrm{c}}$ for LF-PBS vs HF-5

GM-CSF, granulocyte-macrophage colony-stimulating factor; MCP-1, monocyte chemotactic protein-1

\section{Discussion}

Growth hormone treatment resulted in significant improvements in body composition with higher doses showing the greatest improvements. Over the 6 week treatment period, a significant reduction in fat mass and a significant increase in lean mass were observed, even though these mice had free access to a high-fat diet during the treatment period. Surprisingly, growth hormone treatment significantly improved several, but not all indicators of diabetes. Thus the higher doses of growth hormone drastically improved fasting blood glucose levels and glucose tolerance in the high-fat fed mice, reducing them to the level seen in the low-fat fed controls. Growth hormone treatment also reduced liver triacylglycerol content. Despite treatment with increasing doses of growth hormone, hyperinsulinaemia did not worsen.

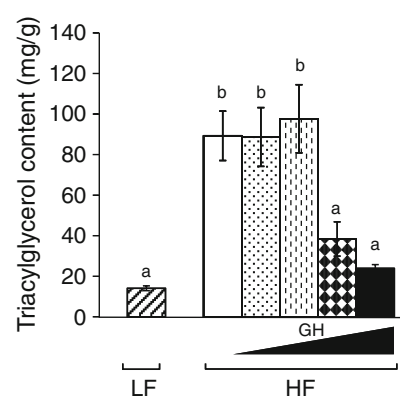

Fig. 5 Triacylglycerol content of livers from mice on the low-fat (LF) diet injected with PBS (hatched bars), high-fat (HF) diet injected with PBS (white bars), or in mice on the high-fat diet injected with increasing doses of growth hormone $(\mathrm{GH})$ as follows: $0.005 \mu \mathrm{g} / \mathrm{g}$ (spotted bars), $0.05 \mu \mathrm{g} / \mathrm{g}$ (vertical dashed bars), $0.5 \mu \mathrm{g} / \mathrm{g}$ (chequered bars) or $5 \mu \mathrm{g} / \mathrm{g}$ (black bars). Data are expressed as mean \pm SEM. Means shown with a common superscript letter are not significantly different, $p>0.05$
Several interesting observations regarding body composition were observed. First, improvements in body composition were seen at the highest two doses of growth hormone, even though only the highest dose of growth hormone resulted in elevated circulating IGF-1 levels. Thus, the changes seen in body composition could be due to the action of growth hormone or to the autocrine or paracrine actions of IGF- 1 . The importance of the autocrine or paracrine production of IGF-1 has been well documented in the liver insulin-like growth factor-1-deficient mouse model [20]. Another possibility is that the level of free, but not total IGF-1 could have been altered, since we only measured and reported total IGF-1 in this study. Second, not all adipose depots appeared to be equally responsive to the growth hormone treatment. The subcutaneous (inguinal) and visceral (mesenteric) fat pads were the most impacted, while the epididymal fat pad was least altered with growth hormone treatment. Depot-specific effects of growth hormone have been reported previously [21, 22]. Thus, these data further support the notion that all fat depots should be evaluated independently in studies with growth hormone or other hormonal treatments. Finally, the timing of the change in lean mass vs fat mass was not the same. The decreases in fat mass observed for the highest dose of growth hormone were seen as early as 2 weeks after initiation of growth hormone injection. In contrast, the gains in lean mass became more prominent with each additional week of treatment. The ability of growth hormone to protect mice from diet-induced fat accumulation and to redirect nutrient partitioning away from adipose tissue and into lean tissue has been reported previously in growth hormone transgenic mice $[21,23]$. However, both of these studies used mice engineered to have chronically elevated growth hormone levels, representing more of an acromegalic state, and not a daily dosing therapy as performed in this study. Overall, 
our results show that acute treatment of growth hormone can radically shift body composition and result in significant lean mass gains.

It is well known that growth hormone can exhibit diabetogenic or anti-insulin activities [24]. Indeed, it has been suspected to cause insulin resistance in tissues containing both growth hormone and insulin receptors, such as liver, muscle and fat, all of which [25-28] have been shown to be affected by acute growth hormone administration and to exhibit insulin resistance. The specific mechanisms responsible for insulin resistance caused by growth hormone remain unknown. While some recent findings suggest that phosphoinositide 3-kinase plays a pivotal role [29, 30], others argue against this [27, 28]. Obesity can also lead to an insulin-resistant state; thus, one might expect that growth hormone treatment of obese mice would exacerbate insulin resistance. While the high-fat diet resulted in obesity and type 2 diabetes, growth hormone treatment with a high-fat diet actually improved fasting blood glucose and glucose tolerance.

Numerous clinical studies have reported the impact of growth hormone treatment of obesity on glucose metabolism, with mixed results. The findings reported here are not unprecedented, since improved glucose metabolism has been described in three of 24 clinical trials [5-7]. However, many studies report that growth hormone treatment of obesity has either little to no effect $[8,9,11,12]$ or negative effects [31-34] on glucose metabolism. A recent metaanalysis comparing 24 studies in which growth hormone was used to treat obesity revealed a small increase in fasting plasma glucose and fasting insulin [35]. However, the authors state that the negative impact on glucose and insulin was most notable in studies using interventions of short duration. Studies with longer treatment regimes showed a lesser effect on insulin levels. Furthermore, only a few studies included data on overall insulin resistance and glycaemia [35]. Surprisingly, this meta-analysis also indicated that HOMA-insulin resistance (IR) and $\mathrm{HbA}_{1 \mathrm{c}}$ levels were improved. It concluded that the effect of growth hormone therapy on glucose homeostasis in obesity requires further evaluation in long-term studies [35]. While several studies have reported an increase in insulin and glucose levels, studies reporting insulin sensitivity (usually by measuring glucose disposal rate) generally agree that it is either unaffected or improved by growth hormone treatment $[5,7,36]$. One explanation for the discrepancies in the literature may be the inclusion or exclusion criteria of individuals with diabetes or the degree of insulin resistance. While more than two dozen clinical trials have used growth hormone to treat obesity, only two have reported improvements in glucose and insulin levels, and insulin sensitivity $[5,6]$. Coincidently, these two studies specifically targeted individuals with type 2 diabetes. Therefore, a possible explanation for our results, with reversal of hyperglycaemia and glucose intolerance with growth hormone treatment, is that in a diabetic state with elevated glucose and glucose intolerance, the diabetogenic actions of growth hormone are overshadowed by its beneficial impact on body composition. Since the mice in our study, as well as humans with type 2 diabetes $[5,6]$, responded well to growth hormone therapy despite having hyperglycaemia and impaired glucose tolerance prior to treatment, such an explanation is plausible. Future studies in this model, using mice with varying degrees of insulin resistance and better assessing the degree of insulin resistance with glucose and insulin clamping, will help address this hypothesis.

Clinical studies have used a wide range of growth hormone doses to treat obesity (5-123 IU/week [ $\sim 0.003-$ $0.1 \mathrm{mg} \mathrm{kg}^{-1}$ day $^{-1}$ ]) $[11,37]$, while doses used for humans with type 2 diabetes were $5-11 \mathrm{IU} /$ week $(\sim 0.003-0.007 \mathrm{mg}$ $\mathrm{kg}^{-1}$ day $\left.^{-1}\right)[5,6]$. Unfortunately, a direct comparison of dosages used in this study to those used for humans is not appropriate and can only be considered in terms of relative dosage for several reasons. There are several species differences as mice were treated instead of humans, bovine growth hormone was used instead of human growth hormone and the system used was not homogenous (i.e. mice treated with bovine growth hormone as opposed to humans treated with human growth hormone). This is one of the reasons why such a broad range of growth hormone levels was used in this study to ensure we reached a dosage that was biologically relevant. Importantly, the recombinant bovine growth hormone used in this study was active, since dose-dependent effects were seen in vivo. However, it appears that the two lowest doses of growth hormone $(0.05$ and $0.005 \mu \mathrm{g} / \mathrm{g}$ ) provided too little growth hormone activity to result in any physiological changes measured. The two highest doses of growth hormone $(0.5$ and $5.0 \mu \mathrm{g} / \mathrm{g})$ improved body composition, glucose and liver triacylglycerol content, while only the highest dose $(5.0 \mu \mathrm{g} / \mathrm{g})$ was high enough to elevate total IGF-1. Thus these data suggest that it is possible to improve body composition, glucose and liver triacylglycerol content with dosages of growth hormone that are below the threshold required to elevate total IGF-1. For obese adult humans treated with growth hormone, Mekala et al. [35] demonstrated that doses above the median value of $31.1 \mathrm{IU} /$ week $(10.4 \mathrm{mg} /$ week or $0.023 \mathrm{mg} \mathrm{kg}^{-1} \mathrm{day}^{-1}$ ) showed a stronger trend towards increasing serum IGF-1. Based on our results and those of Mekala et al. [35], we would suggest a starting dosage approaching but not exceeding 30 IU per week, subsequently titrating appropriately on the basis of individual IGF-1 response to growth hormone. In other words, optimal therapy would be the highest level of growth hormone that does not result in elevation of IGF-1 above levels appropriate for the patient (age and sex considered). 
It is difficult to determine (due to species differences) exactly how long treatment should be given to humans with type 2 diabetes. However, since changes in body composition occurred well before the 6-week endpoint in mice, it is likely that the improvements to body composition were responsible for the improvements we observed in glucose metabolism. In the two human studies using growth hormone to treat patients with type 2 diabetes, only 12 weeks of growth hormone therapy was needed to improve body composition, fasting blood glucose, insulin and insulin sensitivity [5,6]. While Ahn et al. [6] did not report progression of their data during the 12 weeks, Nam et al. [5] reported glucose and insulin levels at 4-week intervals during the 12-week therapy. They [5] found that an initial increase in insulin occurred at 4 weeks, followed by a progressive decrease in insulin at 8 and 12 weeks. Similarly, glucose only decreased minimally at 4 weeks, with steeper declines occurring at 8 and 12 weeks In humans, therefore, it appears that more than 4 weeks were needed and 12 weeks were sufficient to see improvements. Taken together, it seems sufficient time should be given for growth hormone to improve body composition, as improvements in glucose metabolism are likely to be a result of altered body composition.

In summary, these data show that type 2 diabetes can be significantly improved with growth hormone treatment in a mouse model of diet-induced obesity and type 2 diabetes. These results are similar to those shown in humans with type 2 diabetes $[5,6]$. The use of growth hormone to treat human type 2 diabetes remains highly controversial, despite two clinical trials having shown a positive impact on glucose homeostasis $[5,6]$. It would therefore be important to develop an animal model, as shown here, to investigate more fully the impact of growth hormone treatment on specific tissues and conditions, such as fatty liver, as well as to better determine the mechanisms by which growth hormone impacts on type 2 diabetes. While our data do not advocate the use of growth hormone to treat humans with type 2 diabetes, they do provide a model to better evaluate the efficacy and safety of its use and may be used to elucidate the mechanisms involved.

Acknowledgements This work was supported in part by the State of Ohio's Eminent Scholar Program, which includes a gift from alumni of Ohio University (M. and L. Goll), and by grants from the Ohio University Research Committee, AMVETS, the Diabetes Research Initiative and the BioMolecular Innovation and Technology Partnership at Ohio University, the World Anti-Doping Agency and the National Institutes of Health (DK075436-01 and AG019899-06). The authors thank G. Bogosian of the Monsanto Company for donating the recombinant bovine growth hormone used in this study; thanks also to R. Male-Brune for her helpful comments.

Duality of interest The authors declare that there is no duality of interest associated with this manuscript.

\section{References}

1. Bengtsson BA, Johannsson G (1998) The use of growth hormone in adults: a review of the last 10 years, the present and a perspective for the future. Growth Horm IGF Res 8(Suppl B):27-35

2. Veldhuis JD, Roemmich JN, Richmond EJ et al (2005) Endocrine control of body composition in infancy, childhood, and puberty. Endocr Rev 26:114-146

3. Houssay B (1936) The hypophysis and metabolism. N Engl J Med 214:961-985

4. Jorgensen JO, Krag M, Jessen N et al (2004) Growth hormone and glucose homeostasis. Horm Res 62(Suppl 3):51-55

5. Nam SY, Kim KR, Cha BS et al (2001) Low-dose growth hormone treatment combined with diet restriction decreases insulin resistance by reducing visceral fat and increasing muscle mass in obese type 2 diabetic patients. Int J Obes Relat Metab Disord 25:1101-1107

6. Ahn CW, Kim CS, Nam JH et al (2006) Effects of growth hormone on insulin resistance and atherosclerotic risk factors in obese type 2 diabetic patients with poor glycaemic control. Clin Endocrinol (Oxf) 64:444-449

7. Johannsson G, Marin P, Lonn L et al (1997) Growth hormone treatment of abdominally obese men reduces abdominal fat mass, improves glucose and lipoprotein metabolism, and reduces diastolic blood pressure. J Clin Endocrinol Metab 82:727-734

8. Clemmons DR, Snyder DK, Williams R, Underwood LE (1987) Growth hormone administration conserves lean body mass during dietary restriction in obese subjects. J Clin Endocrinol Metab 64:878-883

9. Kamel A, Norgren S, Elimam A, Danielsson P, Marcus C (2000) Effects of growth hormone treatment in obese prepubertal boys. J Clin Endocrinol Metab 85:1412-1419

10. Tomlinson JW, Crabtree N, Clark PM et al (2003) Low-dose growth hormone inhibits 11 beta-hydroxysteroid dehydrogenase type 1 but has no effect upon fat mass in patients with simple obesity. J Clin Endocrinol Metab 88:2113-2118

11. Albert SG, Mooradian AD (2004) Low-dose recombinant human growth hormone as adjuvant therapy to lifestyle modifications in the management of obesity. J Clin Endocrinol Metab 89:695-701

12. Richelsen B, Pedersen SB, Kristensen K et al (2000) Regulation of lipoprotein lipase and hormone-sensitive lipase activity and gene expression in adipose and muscle tissue by growth hormone treatment during weight loss in obese patients. Metabolism 49:906-911

13. Thompson JL, Butterfield GE, Gylfadottir UK et al (1998) Effects of human growth hormone, insulin-like growth factor I, and diet and exercise on body composition of obese postmenopausal women. J Clin Endocrinol Metab 83:1477-1484

14. Surwit RS, Kuhn CM, Cochrane C, McCubbin JA, Feinglos MN (1988) Diet-induced type II diabetes in C57BL/6J mice. Diabetes 37:1163-1167

15. Surwit RS, Feinglos MN, Rodin J et al (1995) Differential effects of fat and sucrose on the development of obesity and diabetes in C57BL/6J and A/J mice. Metabolism 44:645-651

16. Qiu L, List EO, Kopchick JJ (2005) Differentially expressed proteins in the pancreas of diet-induced diabetic mice. Mol Cell Proteomics 4:1311-1318

17. List EO, Berryman DE, Palmer AJ et al (2007) Analysis of mouse skin reveals proteins that are altered in a diet-induced diabetic state: a new method for detection of type 2 diabetes. Proteomics 7:1140-1149

18. List EO, Berryman DE, Palmer AJ et al (2007) Application of bioinformatics and scalable computing to perform proteomic analysis of stomach tissue from diabetic mice. Scalable Computing 8:173-183 
19. Salmon DM, Flatt JP (1985) Effect of dietary fat content on the incidence of obesity among ad libitum fed mice. Int J Obes 9:443449

20. Yakar S, Liu JL, Stannard B et al (1999) Normal growth and development in the absence of hepatic insulin-like growth factor I. Proc Natl Acad Sci U S A 96:7324-7329

21. Berryman DE, List EO, Kohn DT et al (2006) Effect of growth hormone on susceptibility to diet-induced obesity. Endocrinology 147:2801-2808

22. Berryman DE, List EO, Coschigano KT et al (2004) Comparing adiposity profiles in three mouse models with altered $\mathrm{GH}$ signaling. Growth Horm IGF Res 14:309-318

23. Olsson B, Bohlooly YM, Fitzgerald SM et al (2005) Bovine growth hormone transgenic mice are resistant to diet-induced obesity but develop hyperphagia, dyslipidemia, and diabetes on a high-fat diet. Endocrinology 146:920-930

24. Clemmons DR (2002) Roles of insulin-like growth factor-I and growth hormone in mediating insulin resistance in acromegaly. Pituitary 5:181-183

25. Rabinowitz D, Klassen GA, Zierler KL (1965) Effect of human growth hormone on muscle and adipose tissue metabolism in the forearm of man. J Clin Invest 44:51-61

26. Yakar S, Setser J, Zhao H et al (2004) Inhibition of growth hormone action improves insulin sensitivity in liver IGF-1deficient mice. J Clin Invest 113:96-105

27. Jessen N, Djurhuus CB, Jorgensen JO et al (2005) Evidence against a role for insulin-signaling proteins PI 3-kinase and Akt in insulin resistance in human skeletal muscle induced by short-term GH infusion. Am J Physiol Endocrinol Metab 288:E194-E199

28. Nielsen C, Gormsen LC, Jessen N et al (2008) Growth hormone signaling in vivo in human muscle and adipose tissue: impact of insulin, substrate background, and growth hormone receptor blockade. J Clin Endocrinol Metab 93:2842-2850
29. del Rincon JP, Iida K, Gaylinn BD et al (2007) Growth hormone regulation of p85alpha expression and phosphoinositide 3-kinase activity in adipose tissue: mechanism for growth hormonemediated insulin resistance. Diabetes 56:1638-1646

30. Barbour LA, Mizanoor Rahman S, Gurevich I et al (2005) Increased P85alpha is a potent negative regulator of skeletal muscle insulin signaling and induces in vivo insulin resistance associated with growth hormone excess. J Biol Chem 280:37489-37494

31. Snyder DK, Clemmons DR, Underwood LE (1988) Treatment of obese, diet-restricted subjects with growth hormone for 11 weeks: effects on anabolism, lipolysis, and body composition. J Clin Endocrinol Metab 67:54-61

32. Snyder DK, Underwood LE, Clemmons DR (1990) Anabolic effects of growth hormone in obese diet-restricted subjects are dose dependent. Am J Clin Nutr 52:431-437

33. Snyder DK, Underwood LE, Clemmons DR (1995) Persistent lipolytic effect of exogenous growth hormone during caloric restriction. Am J Med 98:129-134

34. Richelsen B, Pedersen SB, Borglum JD et al (1994) Growth hormone treatment of obese women for 5 wk: effect on body composition and adipose tissue LPL activity. Am J Physiol 266: E211-E216

35. Mekala KC, Tritos NA (2009) Effects of recombinant human growth hormone therapy in obesity in adults: a meta-analysis. J Clin Endocrinol Metab 94:130-137

36. Franco C, Brandberg J, Lonn L et al (2005) Growth hormone treatment reduces abdominal visceral fat in postmenopausal women with abdominal obesity: a 12-month placebo-controlled trial. J Clin Endocrinol Metab 90:1466-1474

37. Lucidi P, Parlanti N, Piccioni F, Santeusanio F, de Feo P (2002) Short-term treatment with low doses of recombinant human GH stimulates lipolysis in visceral obese men. J Clin Endocrinol Metab 87:3105-3109 